\title{
On the Electric Conductivity of Homoionic Montmorillonites at Low Water Content
}

\author{
Nelson Juan García \\ Department of Chemistry, INQUISUR CONICET-UNS, University National of Sur, Bahia Blanca B8000CPB, Argentina
}

\begin{abstract}
Bibliographic reports on the electric conductivity of pure homoionic montmorillonite at low water content were analyzed in order to stress a general behavior of conductivity. At low water content, the conductivity is attributed to a mechanism of charge transport involving protons due to the influence of the electric field of the exchangeable cations on water molecules at the solvation shell. Conductivity was analyzed in relation with the polarizing power (ionic potential) of the exchangeable cations and with the influence of the connectivity within samples. The general conclusion stressed is that the connectivity due to the association between 2:1 unit layers (clay fabric) is the main factor on the experimental or "macroscopic" electric conductivity of pure homoionic montmorillonite at low water content. Considerations on the experimental conditions of different bibliographic reports were also made. The conclusion and the considerations made on experimental conditions are a good starting point for future researches on electric conductivity of homoionic montmorillonite at low water content.
\end{abstract}

Key words: Electrical conductivity, homoionic pure montmorillonite, ionic potential, proton, connectivity, association between $2: 1$ unit layers.

\section{Introduction}

Montmorillonite is a clay mineral made up of unit layers of an octahedral sheet of alumina between two tetrahedral sheets of alumina (2:1 unit layer) with cation exchange capacity. This clay which is widely used in the industry and plays an important role on the physicochemical properties of soils has also been studied as solid electrolyte [1-6]. Regardless of the attention attracted on montmorillonite as solid electrolyte, its electrical properties in itself deserve to be studied. Among the electrical properties already studied is the conductivity on compacted tablets of purified homoionic montmorillonites (from different origins) after removal of impurities such as quartz and feldspar and free of electrolytes, at the under saturation domain $\left(p / p_{0}<1\right)$ [1-9]. The authors concluded that the conductivity was mainly due to the transport of charge via protons. At the under saturation domain $\left(p / p_{0}<1\right)$, relative humidity $(\mathrm{RH})$ is under $100 \%$ and water

Corresponding author: Nelson Juan García, Ph.D., main research field: electrical properties of clay minerals. content at both branches of the hysteresis loop of the isotherms of adsorption is lower than $30 \%$ [10-12]. In that range of water content, water is mainly located at the surface of the montmorillonite, strongly influenced by the surface of the clay which includes exchangeable cations with restricted mobility. In that situation, water at the solvation shell of exchangeable cations is under the influence of the electric field of the cations, which increases the probability of polarization of water and the releasing of protons. This effect is reinforced when an external electric field is applied; a condition present when measurements of conductivity are carried out.

Polarization of solvating water was observed by infrared (IR) spectroscopy on homoionic montmorillonites such as alkaline and alkaline-earth montmorillonites [13, 14], on K-, Na-, Co- and Cu-montmorillonites [15] and lanthanide [16]. According to Poinsignon [13], the factors governing IR absorption by water are correlated to water-molecule acidity, and the estimates of the $p K$ of the cation hydration shell confirmed a low dissociation degree 
which is related with the polarizing power of the exchangeable cation. In agreement with this conclusion are the data summarized in Ref. [17]: $p K$ values increase with the polarizing power for most alkaline, alkaline earth elements and lanthanum $(p K=-\log K$, where $K$ is the equilibrium constant for the process of releasing protons).

Electric conductivity of montmorillonites via protons (also known as protonic conductivity) was explained by Slade [1] and Poinsignon [3] with a mechanism where the released protons are propelled by water molecules on the surface of the 2:1 unit layers through two rotational motions: (a) rotation of the hydrate of the cation around the c-axis on the hexagonal hole of the clay layer and (b) rotation of the water molecules of the hydrate, and a translational jump of about $2.8 \AA$. The mechanism, as it was explained by Slade [1] and Poinsignon [3], is confined to the surface of the 2:1 unit layer.

On the other hand, experimental research carried out in our lab $[4,5]$ found agreement between the trend of the polarizing power of exchangeable cations and conductivity on Na- and Li-montmorillonite but no agreement when La-montmorillonite was also considered, i.e. $\mathrm{La}^{3+}<\mathrm{Na}^{+}<\mathrm{Li}^{+}$. Measurements of electric conductivity are carried out on samples made of aggregates and particles due to the association of a large number of 2:1 unit layers. These associations are under the influence of the exchangeable cations located at the interlayer spaces [18]. The association between 2:1 unit layers controls the homogeneity and connectivity within samples of montmorillonite at low water content [19]. High connectivity implies charge transport through larger distances giving higher conductivities according to the mathematical expression of Helmy [20]. This was used to explain our measurements, which is in agreement with the research findings of Zabat [19] on mechanical properties of montmorillonites: cations such as $\mathrm{La}^{3+}, \mathrm{Al}^{3+}$ and $\mathrm{Cs}^{+}$ lead to a heterogeneous internal texture with large total porosity, while cations such as $\mathrm{Li}^{+}$and $\mathrm{Na}^{+}$lead to a homogeneous internal texture characterized by a compact structure and small total porosity, which allows a better long-range defect-free connectivity. An intermediate behavior was found on homoionic montmorillonites with divalent cations of alkaline-earth group [19] and potassium [21]. On the other hand, connectivity and conductivity can be improved rising the water content, by means of molecules that are not at the hydration shell of the exchangeable cations (filling water molecules), both at interlayer spaces and between clay aggregates $[5,9]$. In this situation, the mechanism under consideration resembles the traditionally known as Grotthuss mechanism for the transport of charge by protons [22] and hydroxide ions [23].

Taking account of considerations made above, two levels of conductivity via protons can be thought: one at microscopic level, the second at macroscopic or experimental level. The first one was the result of the transport of charge confined to the surface of the 2:1 unit layers. The second one was the result of the influence of type of association between 2:1 unit layers on the transport of charges.

The aim of the paper is to stress whether the results found at our lab can be ascribed to a general behavior of conductivity at low water content. To achieve this, they will be merged with conductivity reports from bibliography related with the transport of charge via protons. The set will be analyzed in relation to the polarizability of water at the exchangeable cations and the association between unit layers.

\section{Polarization and Ionic Potential}

Since a cation is a charged particle, its positive electric field is able to polarize water molecules at its hydration shell. Then cations with electric fields of increasing strength lead to an increasing degree of polarization, becoming more probable release of protons according to the Eq. (1):

$\left[\mathrm{Me}\left(\mathrm{H}_{2} \mathrm{O}\right)_{x}\right]^{n+} \leftrightarrows\left[\mathrm{Me}\left(\mathrm{H}_{2} \mathrm{O}\right)_{x-1} \mathrm{OH}\right]^{(n-1)+}+\mathrm{H}^{+}(1)$

Since the equilibrium is displaced to the left hand 
side, $K$ also increases. Baes and Messmer [24], onto electrostatic bases, found a mathematical expression between $\log \mathrm{K}$ and the ionic potential of cations $(z / r)$.

$$
\log K=B \frac{z}{r}-A
$$

Where $z$ is the charge and $r$ is the radius of cations.

Values of $-\log K(p K)$ have been summarized in references [17, 24, 25]. For instance, values of $-\log K$ for cations such as $\mathrm{Na}^{+}, \mathrm{Li}^{+}, \mathrm{Ba}^{2+}, \mathrm{Sr}^{2+}, \mathrm{Ca}^{2+}, \mathrm{Mg}^{2+}$ and $\mathrm{La}^{3+}$ are $14.48,13.82,13.47,13.18,12.70,11.42$ and 10.70 respectively. When these values are plotted as $\log K$ against ionic potential (Fig. 1), it is found that Log $K$ increases linearly from $\mathrm{Na}^{+}$to $\mathrm{La}^{3+}$. That is to say, the polarization of water molecules at the solvation shell increases with the ionic potential of such cations.

\section{Macroscopic Conductivity and Ionic Potential}

According to the series presented above, when conductivity is confined to the surface of the $2: 1$ unit layers (microscopic conductivity), it follows the trend: $\mathrm{Na}^{+}<\mathrm{Li}^{+}<\mathrm{Ba}^{2+}<\mathrm{Sr}^{2+}<\mathrm{Ca}^{2+}<\mathrm{Mg}^{2+}<\mathrm{La}^{3+}$. This can be thought as somewhat promising for developing new solid-state ionics. Experimental research on this subject carried out at our lab [4, 5], however, revealed that the trend of macroscopic conductivity can be somewhat different. Conductivities of montmorillonite with exchangeable cations at both ends of the series: $\mathrm{Na}^{+}, \mathrm{Li}^{+}$and $\mathrm{La}^{3+}$, gave $\mathrm{La}^{3+}<\mathrm{Na}^{+}<\mathrm{Li}^{+}$. In order to stress whether this sequence follows a more general behavior of conductivities via protons at low water content, they are merged (Fig. 2) with conductivity reports from cations already analyzed against ionic potential [1, 2, 9]. Conductivities of $\mathrm{Zn}-, \mathrm{Cu}-, \mathrm{Ni}-$ and Cr-montmorillonites were also included in Fig. 2. In these exchangeable cations, there is moreover present an increasing degree of covalence between cation and solvating water (computed in the value of A) resulting in higher values of $\log K$ than the alkaline, alkaline-earth and lanthanum group.

At the first sight, what can be observed in Fig. 2 is a scattering of conductivities for each exchangeable cation; this can be attributed to factors related with the experimental conditions of measurements which will be considered latter.

However, after analyzing the whole set of conductivities, it is found that the behavior of our

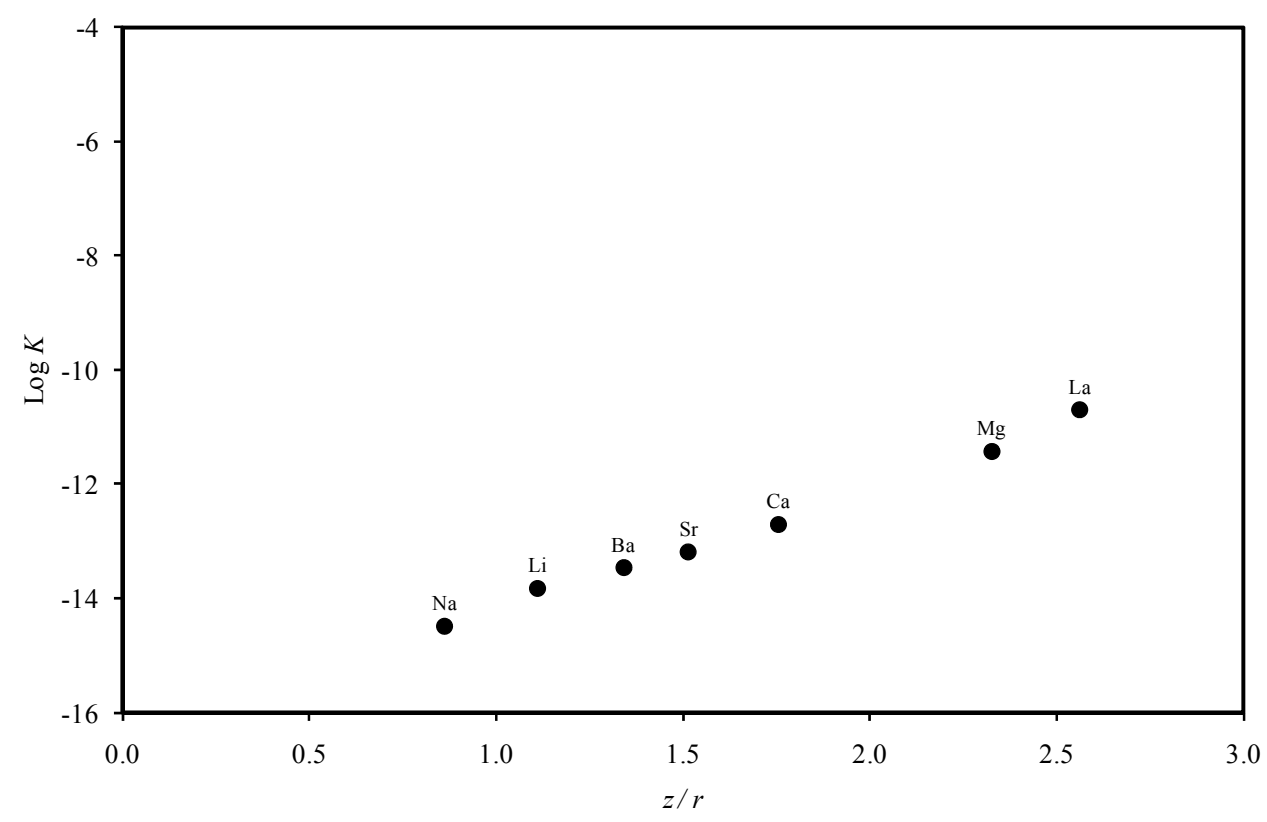

Fig. 1 Logarithm of $K(\log K)$ against ionic potential of cations $(z / r)\left(\AA^{-1}\right)$. Where $z$ is the charge and $r$ is the radius of cations. 


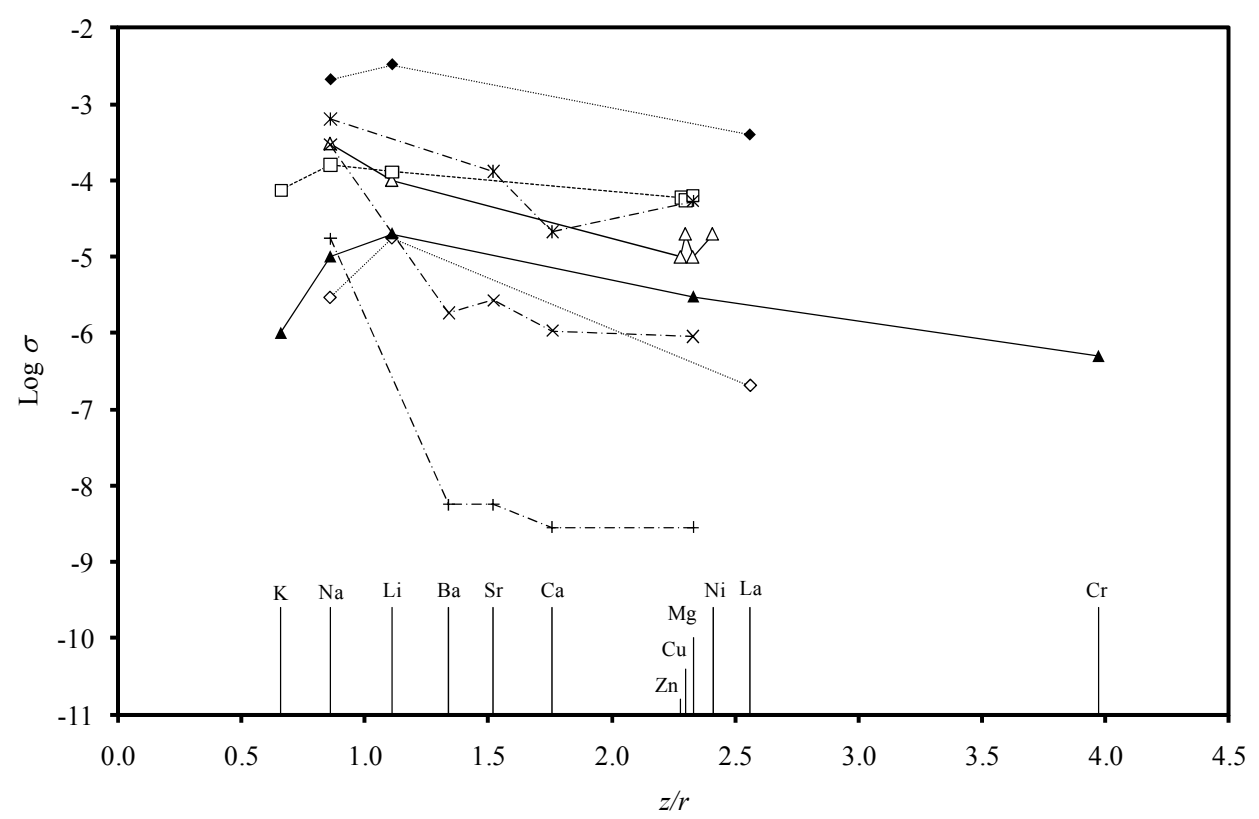

Fig. 2 Logarithm of $\sigma(\log \sigma)$ against ionic potential $(z / r)\left(\AA^{-1}\right), \sigma$ : experimental "or macroscopic" electric conductivity of homoionic montmorillonites in $S \cdot \mathbf{c m}^{-1}$. Labels and vertical lines on the horizontal axis indicate the ionic potential of cations. Data from Ref. [1] $(\Delta)$ and $(\Delta)$ are from Clay A and Clay B respectively. Data from Ref. [2] ( $\square$ ). Data from Refs. [4] and [5] $(\diamond)$ and $(\diamond)$ at $p / p_{0} 0.22$ and 0.85 respectively. Data from Ref. [9] $(+),(\times)$ and $(*)$, at $5 \%, 20 \%$ and $30 \%$ water content respectively.

samples can be ascribed to a more general one where connectivity due to the association between 2:1 unit layers (clay fabric) is the prevailing factor on the "macroscopic conductivity" of montmorillonites at low water content. Li- and Na-montmorillonites give the higher conductivities because they present the best connectivity.

In relation with those factors that can contribute to the scattering of conductivity for each exchangeable cation, it is interesting to make a brief account of them since they can be associated with the origin of montmorillonites and with the experimental conditions of measurement (Table 1). In relation with the origin of the sample, it can be mentioned the amount and location of charges (both at the octahedral and tetrahedral sheets of the 2:1 unit layer), which are related with cation exchange capacity and swelling of montmorillonite respectively [26]. In relation with the experimental conditions of measurements (factors that can be susceptible of standardization), it can be thought that preparation of tablets priors to measurement and technique of conductivity measurement itself.
With respect to factors linked with preparation of tablets, procedure of hydration and pressing of samples can be cited. The hydration procedure is a point that has to be considered because isotherms of adsorcion-desorcion display hysteresis loops and water is involved in the mechanism of charge transport. In this sense, a sample located at the same relative humidity can be at the adsorption or desorption branch, which means a different amount of "filling water" and therefore a different value of conductivity. In relation with pressing, a characteristic that emerges from the experimental methods (Table 1) is the wide range of pressures applied to obtain the tablets. From Fig. 2, it can be seen that the set of tablets obtained at the higher pressures [2] give the lower dispersion of conductivity. Accordingly, it could be concluded that connectivity of montmorillonite can be improved by pressing. To end with experimental issues, the way that measurements of conductivity are carried out also contributes to the scattering of data. For instance, in some papers, conductivity was calculated from values of resistance measured at a fixed frequency, while in others, it was 
Table 1 Experimental condition of electrical conductivity measurements.

\begin{tabular}{|c|c|c|c|c|}
\hline Reference & $\begin{array}{l}\text { Pressure } \\
\left(\mathrm{kg} / \mathrm{cm}^{2}\right)\end{array}$ & $\begin{array}{l}\text { Temperature } \\
\left({ }^{\circ} \mathrm{C}\right)\end{array}$ & Preparation of homoionic montmorillonites & Electrode-tablet assembly \\
\hline [1] & 6,000 & 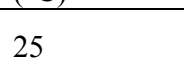 & $\begin{array}{l}\text { Tablet into a sealed glass tube after pressing } \\
\text { powder dried under vacuum }\end{array}$ & Electrodes painted on surface of tablets \\
\hline [2] & 10,000 & 22 & Tablet from dry powder & Electrodes painted on surface of tablets \\
\hline [4], [5] & 2,000 & 25 & $\begin{array}{l}\text { Tablet at different } p / p_{0} \text {, after pressing } \\
\text { powder at } p / p_{0}=1\end{array}$ & $\begin{array}{l}\text { Hydrated powder pressed between } \\
\text { electrodes }\end{array}$ \\
\hline [9] & 30 & 20 & $\begin{array}{l}\text { Tablet at different } p / p_{0} \text {, after pressing } \\
\text { dry powder }\end{array}$ & Tablet placed between electrodes \\
\hline
\end{tabular}

calculated through impedance spectroscopy from Nyquist plots. In this technique, conductivity is calculated from impedance $(z)$ data collected over a wide range of frequencies in alternating current, with specific software [6]. What closely related to measurements is the adhesiveness of the tablet to the conductive foil (electrode) that establishes the electrical contact with the external electric circuitry. A poor adhesiveness develops an "air gap" capacitance between tablet and electrode, which decreases the value of conductivity.

\section{Conclusion}

In spite of considerations made above in relation with the scattering of data, authors worked systematically on each report; the set of conductivities (Fig. 2) follow a general behavior to which our results can be ascribed. In this behavior, the connectivity due to the association between 2:1 unit layers (clay fabric) has a prevailing role over the polarizability of water at the exchangeable cations on the "macroscopic conductivity" of montmorillonites at low water content. Under this condition, lithium and sodium montmorillonites give the higher electrical conductivities.

The mechanism here considered is for water content lower than $30 \%$; it seems no pertinent to be discussed at higher values. On the other hand, the effect of the association of montmorillonite layers on the electrical conductivity was also observed at higher water content [27].

\section{References}

[1] Slade, R. T., Barker, J., Hirst, R., Halsteadt, T. K., and Reid, P. I. 1987. "Conduction and Diffusion in
Exchanged Montmorillonite Clays.” Solid State Ionics 24 (4): 289-295.

[2] Boutehala, M., and Tejdar, F. 1993. "Applications of Exchanged Montmorillonite as Solid Electrolyte." Solid State Ionics 61 (1): 257-263.

[3] Poinsignon, C. 1997. "Protonic Conductivity and Water Dynamics in Swelling Clays.” Solid State Ionics 97 (1): 399-407.

[4] García, N. J., and Bazán, J. C. 1996. "Conductivity in $\mathrm{Na}^{+}-$and $\mathrm{Li}^{+}$-montmorillonite as a Function of Equilibration Humidity." Solid State Ionics 92 (1): 139-143.

[5] García, N. J., and Bazán, J. C. 2009. "Electrical Conductivity of Montmorillonite as a Function of Relative Humidity: La-montmorillonite." Clay Minerals 44 (1): 81-88.

[6] García, N. J. 2016. "Electrochemical Impedance Spectroscopy of Sodium Montmorillonite with Decreasing Water Content." In 53rd Annual Meeting of the Clay Minerals Society, 34-35.

[7] Fripiat, J. J., Jelli, A., Poncelet, G., and Andre, J. 1965. "Thermodynamic Properties of Adsorbed Water Molecules and Electrical Conduction in Montmorillonites and Silicas." Journal of Physical Chemistry 69 (7): 2185-2197.

[8] Calvet, R., and Mamy, J. 1971. "On the Nature of the Charges Responsible for the Electrical Conductivity of Clays." Comptes Rendus Academie des Sciences Paris Série D 273: 1251-1253.

[9] Calvet, R. 1975. "Dielectric Properties of Montmorillonites Saturated by Bivalent Cations." Clays and Clay Minerals 23 (4): 257-265.

[10] Mooney, R. W., Kenan, A. G., and Wood, L. A. 1952. "Adsorption of Water Vapor by Montmorillonite. II. Effect of Exchangeable Ions and Lattice Swelling as Measured by X-ray Diffraction." Journal of the American Chemical Society 74 (6): 1371-1374.

[11] Berend, I., Cases, J. M., Francois, M., Uriot, J. P., Michot, L., Maison, A., et al. 1995. "Mechanism of Adsorption and Desorption of Water Vapor by Homoionic Montmorillonites: 2. The $\mathrm{Li}^{+}, \mathrm{Na}^{+}, \mathrm{K}^{+}, \mathrm{Rb}^{+}$and $\mathrm{Cs}^{+}$-exchanged Forms." Clays and Clay Minerals 43 (3): 
324-336.

[12] Cases, J. M., Berend, I., Francois, M., Uriot, J. P., Michot, L., and Thomas, F. 1997. "Mechanism of Adsorption and Desorption of Water Vapor by Homoionic Montmorillonite: 3. the $\mathrm{Mg}^{2+}, \mathrm{Ca}^{2+}, \mathrm{Sr}^{2+}$ and $\mathrm{Ba}^{2+}$ Exchanged Forms." Clays and Clay Minerals 45 (1): 8-22.

[13] Poinsignon, C., Cases, J. M., and Fripiat, J. J. 1978. "Electrical Polarization of Water Molecules Adsorbed by Smectites. An Infrared Study." Journal of Physical Chemistry 82 (16): 1855-1860.

[14] Xu, W., Johnston, C. T, Parker, P., and Agnew, S. F. 2000. "Infrared Study of Water Sorption on Na-, Li-, Caand Mg-exchanged (SWy-1 and SAz-1) Montmorillonita." Clays Clay Minerals 48 (1): 120-131.

[15] Johnston, C. T., Sposito, G., and Erickson, C. 1992. "Vibrational Probe Studies of Water Interactions with Montmorillonita.” Clays Clay Minerals 40 (6): 722-730.

[16] Mozas, T., Bruque, S., and Rodriguez, A. 1980. "Effect of Thermal Treatment on Lanthanide Montmorillonites: Dehydration." Clay Minerals 15 (4): 421-428.

[17] Huheey, J. E., Keiter, E. A., and Keiter, R. L. 1993. Inorganic Chemistry, Principles of Structure and Reactivity. New York: Harper Collins.

[18] Sposito, G. 1984. The Surface Chemistry of Soils. New York: Oxford University Press.

[19] Zabat, M., Vayer-Besançon, M., Harba, R., Bonnamy, S., and Van Damme, H. 1997. "Surface Topography and Mechanical Properties of Smectite Films." Progress in Colloid Polymer Science 105: 96-102.

[20] Helmy, A. K. 1974. "Surface Conductance in Plugs." Electroanalytical Chemistry and Interfacial Electrochemistry 52 (2): 287-290.

[21] Roy, G., Pelletier, M., Thomas, F., Despas, C., and Bessiere, J. 2000. "Aggregation in Na-, K-, Ca-montmorillonite Dispersions, Characterized by Impedance Spectroscopy." Clay Minerals 35 (2): 335-343.

[22] Marx, D. 2006. "Proton Transfer 200 Years after von Grotthuss: Insights from Ab Initio Simulations." Chem. Phys. Chem. 7 (9): 1848-1870.

[23] Agmon, N. 2000. "Mechanism of Hydroxide Mobility." Chemical Physics Letters 319 (3): 247-252.

[24] Baes, Ch. F., and Mesmer, R. E. 1976. The Hydrolysis of Cations. New York: John Wiley \& Sons.

[25] Burgess, J. 1978. Metal Ions in Solution. London: John Wiley \& Sons.

[26] Slade, P. G., and Quirk, J. P. 1991. "The Limited Crystalline Swelling of Smectites in $\mathrm{CaCl}_{2}, \mathrm{MgCl}_{2}$ and $\mathrm{LaCl}_{3}$ Solutions." Journal of Colloid and Interface Science 144 (1): 18-26.

[27] Kaufhold, S., Dohrmann, R., Klinkenberg, M., and Noell, U. 2015. "Electrical Conductivity of Bentonites." Applied Clay Science 114: 375-385. 